\title{
Developing Internet Document Model for Finding Innovative Elements in Traveling
}

\author{
Mu-Hua Lin, Chao-Fu Hong, Woo-Tsong Lin \\ Department of Management Information Systems, National Chengchi University, Taiwan \\ Email:95356503@nccu.edu.tw
}

Received 19 February 2016; accepted 23 April 2016; published 26 April 2016

Copyright (C) 2016 by authors and Scientific Research Publishing Inc.

This work is licensed under the Creative Commons Attribution International License (CC BY). http://creativecommons.org/licenses/by/4.0/

(c) (i) Open Access

\begin{abstract}
In order to survive for a longer time, enterprises have to find the rare and valuable information at the early stage. In Web 2.0, consumers can easily share their consumer-related articles on Internet blogs. Therefore, there is big consuming data on the Internet. Additionally, consumer co-creation, for a variety of reasons, can be seen as an attractive approach for firms in developing new services. In particular, ideas generated through consumer co-creation will more closely mirror consumers' needs. In the present study, we develop a new virtual textual brainstorming framework by obtaining traveling data from the Internet, use text mining and by following the 4 modes of the Internet Document model, to investigate the traveler' needs or creations and to aid the authors in designing innovative traveling services. Finally, the innovative traveling services are suggested to travelers, and about $63 \%$ travelers can accept it. The examining results are evidence and our model is useful for creating innovative service.
\end{abstract}

\section{Keywords}

Co-Creation, Consuming Tribe, Lead User, Innovative Idea, Knowledge Spiral Model

\section{Introduction}

Innovation is a new idea or way of doing something. [1] proposed the innovation diffusion model (IDM) and defined "innovation" as "an idea, practice, or object that is perceived as new by an individual or other unit of adoption". Moreover, the idea of innovation can be better understood as a process in which a firm creates and defines a problem and then actively develops new ideas to solve the problem [2]. In other words, innovation is not only the static meaning of a new idea, but also discovering the process of a new idea. Furthermore, in [3]'s experiment, only about $26 \%$ of the consumers modify a commercial interest and are directly involved in the innovative development of a product. [4] and [5] also demonstrated that among firms with millions of consumers, 
only relatively few consumers were willing to be fully engaged in or have the skills necessary to help in the development of a product. In addition, in the IDM, only about $20 \%$ of all consumers have consuming characteristics similar to the innovators and early adopters [1]. These experimental results show that only a few consumers; namely, lead users, are able to create new ways of using innovative products that lead to the popularity of the products [6]. However, before firms attempt to design an innovative product, they seldom know who the lead user is [4] [7]. In sum, if firms attempt to create innovation, two problems must be solved: the first is how to develop a method for finding creative lead users, and the second is how to discover relevant hetero-data to recombine new ideas.

Fortunately, especially in the era of Web 2.0, it is easy for consumers to share what they have written about their consumer values on the Internet through blogs social networking sites, wikis, video sharing, host services and web applications, for example. Therefore, many kinds of data, which can create Internet Document, are stored on the Internet. [8] applied co-occurrence analysis with Grounded Theory (GT) [9] to extract the consuming value from the Internet. This study demonstrates that because a lot of consumer information is posted on the Internet, it may be easier, more effective, and less costly to identify a trend from the Internet. This identification of a trend may lead to solving the first question of how to find a method, but the second problem; namely, how to create innovation will still be unsolved.

To overcome the first problem, we develop an Internet Document model, which includes three mechanisms: knowledge creation, GT textual-based data operations, and co-occurrence analysis. First, in knowledge creation, the keywords of research issue related are identified, and then, in our era of Internet Document, the Google blog search is used to collect the related data, such as the data collected when related members are invited to participate in brainstorming meetings. Therefore, when, applying GT and co-occurrence analysis to analyze the relevant consumer's textual data, tacit knowledge will be translated into explicit knowledge. Finally, co-occurrence analysis is used to discover the weak tie that is often used to combine explicit knowledge and generate new knowledge.

In this paper, we use the case study of Tamsui travelling to demonstrate the usefulness of our model. In the first cycle of knowledge creation, only data of one day or half day of Tamsui traveling data was collected. After co-occurrence analysis, the authors can observe that most consumers traveled the old street of Tamsui, Fisherman's Wharf and Fort San Domingo, etc. Even they do not propose their need some special services in Tamsui traveling, the authors also can recognize some characteristics of British are embedded into the Tamsui traveling data, which will be a breakthrough point for creating service chance. Therefore, to collect the consumer's data in British traveling, we ran a second cycle of knowledge creation, where the consumers participated in virtual brainstorming meetings to create knowledge, to understand their special behaviors in British traveling. The authors combined the Tamsui traveling knowledge with the British traveling for creative knowledge to emerge that helped us to design an British style Tamsui traveling scenario. To examine the simplicity and usefulness of our model, the accepting questionnaire was implemented to analyze the acceptance rate of British style Tamsui traveling scenario. Finally, the experimental results of our model showed that allowed at least $63 \%$ of consumers' accepting intention of scenario, which is higher than the consumers' average value 3.5.

\section{Literature Review}

Consumers are able and willing to provide ideas for new goods or services that may fulfill needs that have not yet been met by the market, or they may improve on existing offers [10]. Involving consumers in new product development (NPD) processes generates ideas through co-creation with consumers and will more closely mirror consumers' needs, thereby improving product quality, reducing risk, and increasing market acceptance [11]. It has been clearly recognized that successful NPD depends on a deep understanding of consumers' needs and product development efforts that meet those needs [12]. However, by involving consumers more actively in the NPD process, new ideas for a product can be generated, which are more likely to be valued by consumers, thereby increasing the likelihood of success of a new product. By contrast, only a few lead users are able to create new ways of using innovative products that lead to the popularity of such products [6]. Lead user shares their ideas with others, as a 'tribal identity', to attract people to participate in the consuming tribe [13]. For example, in [3]'s experiment, only about $26 \%$ of the consumers have the "leading edge status" and in-house technical capabilities so that they can freely share their innovations with others, and the characteristics of those consumers are similar to the innovators and early adopters mentioned by Rogers and they occupy only about $20 \%$ of all 
consumers [1]. Therefore, how to sift out the lead users/consumers is a problem of innovation/knowledge creation.

Today's Web 2.0 is the most popular Internet technology; it helps consumers easily share what consuming values they write on the Internet [14]. Furthermore, in 2011 in a report about big data by the McKinsey Global Institute, in 2010 did data increase 7000 PB (petabyte), so they predicted that the 2020 data would be 44 times the 2010. Big data always includes the data of browsing websites, virtual social communication, weblog articles, weather data and transaction data etc. [8] used the Google blog search to sift out related consumer's data, and they also used GT and co-occurrence analysis to extract innovative consuming values from the collected data. Finally, they used the innovative consuming values to influence a majority to accept a new product successfully.

[8]'s model successfully found a new innovative product, but their model could not extend such knowledge to other fields to organize/design new knowledge. Nonaka's Spiral model of knowledge creation [2], which is a famous conceptual knowledge creation method, on the other hand, is able to organize and design new knowledge. In Nonaka's model, there are four modes of creating new knowledge: socialization, externalization, combination and internalization. In the socialization mode, researchers usually start with the building of a team or field of interaction. At the externalization mode, team members articulate their own perspectives, and thereby reveal hidden tacit knowledge through dialogue allowing the tacit knowledge of members to be translated to the explicit knowledge. In the combination mode, explicit knowledge is combined with each other to form new knowledge. Finally, through an iterative process of trial and error, the new knowledge is made concrete in the internalization mode.

In this paper, the authors combine Nonaka's Spiral model of knowledge creation with Lin and Hong's model, and use text mining to extract tacit knowledge from the Internet, translate this tacit knowledge to explicit knowledge, combine all explicit knowledge for knowledge creation, and extend this knowledge to other fields to collect data and to run another analysis cycle.

\section{Research Method}

Consumer co-creation is an important framework for promoting a new service, and the core of this framework is ideas generation, which is similar to Nonaka's Spiral model of knowledge creation. However, the cost and unrestrained ideas by consumer co-creation are problems in developing new services. The present study modifies Nonaka's Spiral model of knowledge creation into a virtual society, to reduce the cost of developing a new service, and based on a firm's knowledge removes unrelated ideas. Furthermore, externalization and combination in Nonaka's Spiral model of knowledge creation is used to generate new ideas. In our model, the authors recognize and integrate the co-occurring data to refine the innovative ideas. In addition, GT is used for text mining as in Lin and Hong's model. However, this study develops a new model for consumer co-creation in the virtual society, which combines the Nonaka's Spiral model of knowledge creation with GT-based text mining. A research model flowchart is shown as follows.

To achieve the goal of developing innovative ways of designing new services, the authors of the present study have developed an Internet Document model to explore such innovative ways by using a Google blog search to obtain relevant consumer textual data and applying GT along with the social identity theory, self-categorization theory, and the co-occurrence analysis method, that may lead humans to conform to the expectations of others.

\subsection{Socialization: Using Innovative Ways to Develop a New Service}

Socialization in this first phase of Figure 1 is similar to a brainstorming meeting. The authors invite related consumers to participate in the meeting. In this case, defining the relation of the social entity is a key factor for solving the problem of developing innovative ways to design a new service. The service's function and physical attributes are very important to discovering domain definition keywords. These keywords are used to collected data from the Internet, and invite the majority of consumers to participate in the brainstorming process. In the next phase, lead users are shifted out to participate in the meeting. The detailed process as follows: $\mathrm{H}$ labels indicate the steps to be done by human beings, and $\mathrm{C}$ labels indicate the steps to be done by computer systems.

Step 1: Processing the raw data

1-1-1_H) The authors define the relevant keywords of a new service.

1-1-1_C) The authors select the data corresponding to keywords from the Internet.

1-1-2_H) Based on his/her domain knowledge, the authors interpret the texts, and at the same time, segment 


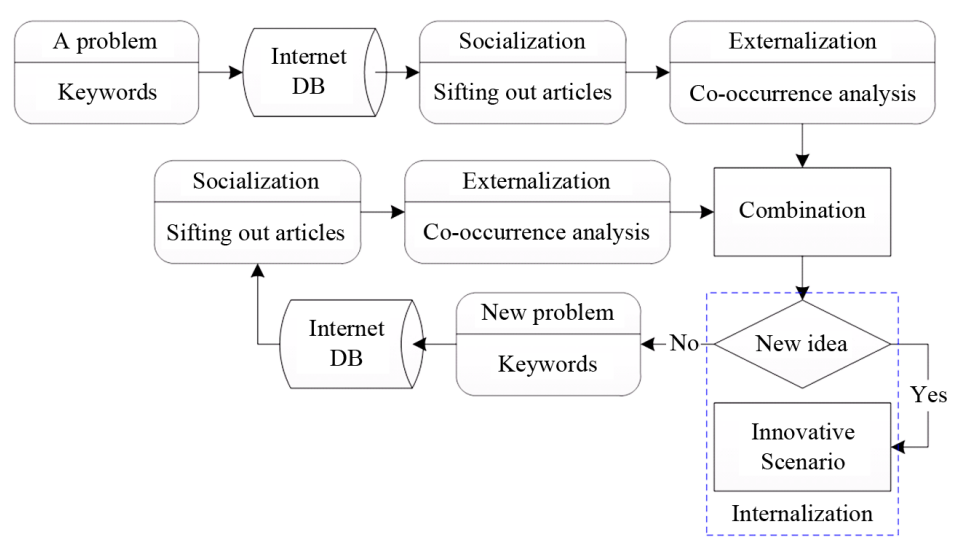

Figure 1. The research flowchart.

texts into words, remove irrelevant words, and mark meaningful words with conceptual labels.

Step 2: Word co-occurrence analysis

1-2-1_C) The authors use Equation (1) to calculate the association values of all relevant words as shown below:

$N$ is all words

$i=1$ to $N-1$

$j=i+1$ to $N$

$$
\operatorname{assoc}\left(w_{i}, w_{j}\right)=\sum \min \left(\left|w_{i}\right|_{s},\left|w_{j}\right|_{s}\right)
$$

In the above Equation (1), $s$ stands for the co-occurrence of words in the sentence, and $D$ stands for all textual data.

1-2-2_C) To visualize the result of the analysis, the computer system can reveal an association diagram showing the association among the co-occurrence words.

1-2-1_H) The authors identify keywords as concepts and the clusters as categories derived from the co-occurrence association diagram, which helps the authors figure out the various preliminary theme values presented in the data.

\subsection{Externalization: Generates Uses of Innovative Service Clusters to Show Explicit Knowledge}

Based on the analysis in phase of socialization, the authors discover various innovative ways of using the consumer's ideas, and then use the innovative ideas to shift out useful data that identifies the lead users, and cluster the data to reveal the leading values, again. The process is illustrated as follows:

$2-1 \_$H) The authors needs to define what the uses of innovative services $\left(w_{\text {innovation }}\right)$ are.

2-1_C) Innovative service use ( $w_{\text {innovation }}$ ) extracts out some rare but meaningful sentences. This variable is used to confirm the theme and to remove irrelevant sentences with a view to narrowing down the data range and to sifting out valid sentences. That is, valid sentences must include words related to $w_{\text {innovation}}$, which is shown as Equation (2).

$i=$ first sentence to the last sentence

$$
\text { Valid sentence set }=\text { if }\left(\left\{w_{1}, w_{2}, \cdots\right\}_{i} \cap\left\{w_{\text {innovation }}\right\}\right) \neq \phi
$$

2-2_C) Use Equation (1) to calculate the association value of all words in the set of valid sentences, and then create an association diagram.

\subsection{Combination: Link Innovative Ideas to Extract Uses of These Services from the Lead Users}

The authors draw a storyline based on links, using clusters developed by the innovative ideas to design an ad- 
vertising scenario to improve the social influence of the information. The process is as follows:

3-1_H) The authors needs to decide what the various uses of the innovative ideas are

$\left(w_{\text {innovation }_{1}}, w_{\text {innovation }_{2}}, \cdots,\right)$.

3-1_C) Various innovative ways of using ideas $\left(w_{\text {innovation }_{1}}, w_{\text {innovation }_{2}}, \cdots\right.$, ) extract the rare but meaningful sentences.

$i=$ first valid sentence to the last valid sentence

$$
\text { use of innovative product set }=\operatorname{if}\left(\left\{w_{1}, w_{2}, \cdots\right\}_{i} \cap\left\{w_{\text {innovation }_{1}}, w_{\text {innovation }_{2}}, \cdots,\right\}\right) \neq \phi
$$

3-2_C) Use Equation (1) to calculate the association value of all words in terms of innovative uses of ideas, and then creates an association diagram.

3-2_H) Based on his/her domain knowledge, the authors identifies the lead users' innovative uses of ideas to create the scenario.

\subsection{Internalization: Refine the Scenario}

Based on the scenario, if the authors can add their domain knowledge into the story, the process returns to Phase socialization, or the authors are satisfied with the storyline and then stop the meeting.

\section{Case Study}

Here, we try to prove that innovative idea discovery based on knowledge spiral model is useful for creating innovative service.

\subsection{First Stage of New Knowledge Discovery}

In addition, because the information is introduced for Taiwanese, only weblog written by Taiwanese is valid. So, the authors collected data posted on blogs relevant to Tamsui travel and Tamsui holiday by Taiwanese. These data ranged from January 1, 2011 to December 31. Using Google blogs (http://blogsearch.google.com/blogsearch) and the keywords are "Tamsui travel" or "Tamsui holiday", to search for the data, the authors obtained 218 related data from blog articles.

1) Socialization: Using innovative ways to develop a new service

To mining innovative idea, firstly, the authors according to on our model preprocesses the data, and uses system to analyze the frequency of word-word co-occurrences to present the words associative diagram, as shown in Figure 2. Then, authors can recognize that the most of travelers come to "Tamsui", they will walk on Old

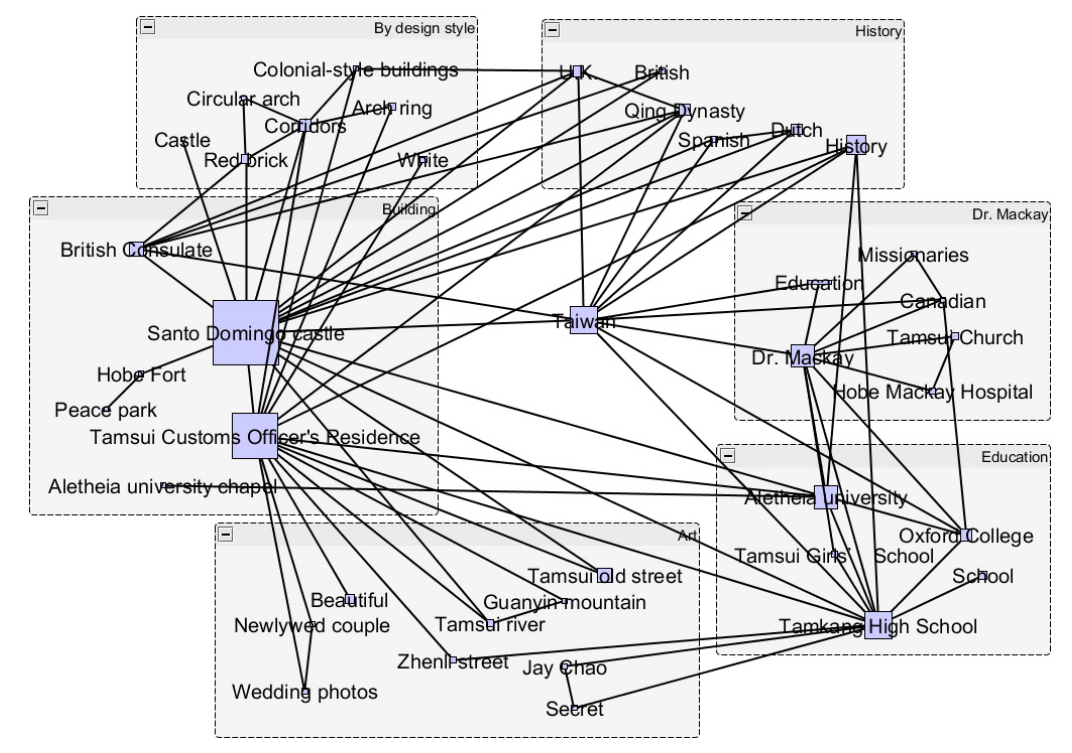

Figure 2. Association analysis of “Tamsui”. 
Street of Tamsui, and then they also go to Fort Santo Domingo to see European colonial style building, stand on Tamsui Oxford College to remember Dr. Mackay. Then, the authors go to next step.

2) Externalization: Generates uses of innovative service clusters to show explicit knowledge

In generating externalization analysis, the authors identify each European colonial building as one concept, and then sifted out concept's data is very clean. Therefore, word frequency and word-word co-occurrence frequency can be set in very low level to externalize all information.

The result of Fort Santo Domingo is shown in Figure 3. Only British consulate and simple colonial history are emerged out to connect with the castle, but lack the history of colonial life that maybe the interesting travel idea. The same analysis method is also used to analyze little white house and Tamsui Oxford College et al., analysis results includes European style buildings, which includes European style constructing, as wing-room, spire, stained glass et al. In addition, there is a beautiful garden in front of the building, such as British manor. And, Dr. Mackay propagated Christianity and educated modern medical for students in Tamsui Oxford College.

3) Combination: Link innovative ideas (weak tie recognition) to extract uses of these services from the lead users

In this step, the authors want to integrate related external associative graphs to clearly sketch the whole (tribe) graph. Then they integrate Tamsui Oxford College, little white house et al., and the characteristics of British manor, such as garden, carved statue, spire, corridors, arch et al., are emerged to bridge the (sub tribes) external associative graphs, as shown in Figure 4. It means that the beauties of European colonial style building can attract consumers to visit these places.

Then, the authors understand that the beauty of British manor is a linking value (midway) to attract Taiwanese for travel. In addition, on experience of traveling other country, the researcher compares the experiential distance between Taiwanese and Taiwanese with Taiwanese and foreigners, and then they believe that the experiential of Taiwanese is more suitable for Taiwanese. Thus, according to knowledge spiral model the authors have perceived the beauty of British manor and Taiwanese, as a hint, to search for innovative information, again.

\subsection{Second Stage of New Knowledge Discovery}

Therefore, only visiting British weblog written by Taiwanese is valid. So, the researchers collected data posted on blogs relevant to British travel and British holiday by Taiwanese. In addition, these data ranged from January 1, 2011 to December 31. Using Google blogs and the keywords, British travel + British holiday, to search for the data, the researchers obtained 67 related data from blog articles. And then, the authors follow socialization and externalization, mining concepts and integrating all concepts to construct the image of Taiwanese traveling United Kingdom (U.K.), as shown in Figure 5.

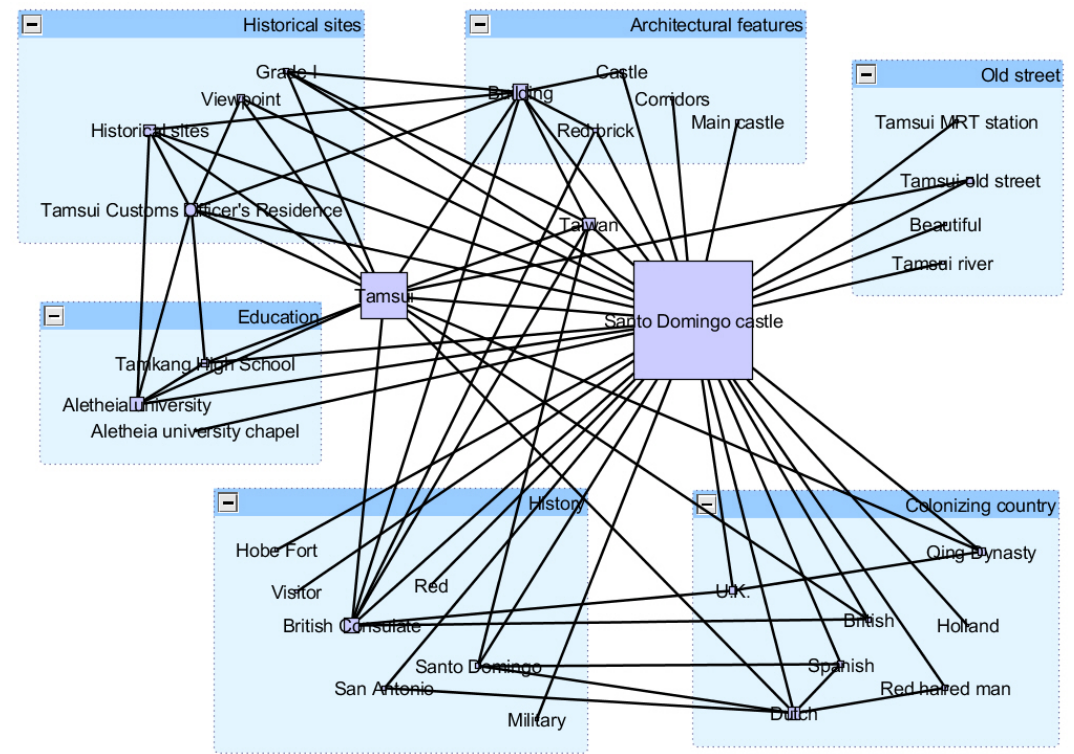

Figure 3. Association analysis focused on "Fort Santo Domingo". 


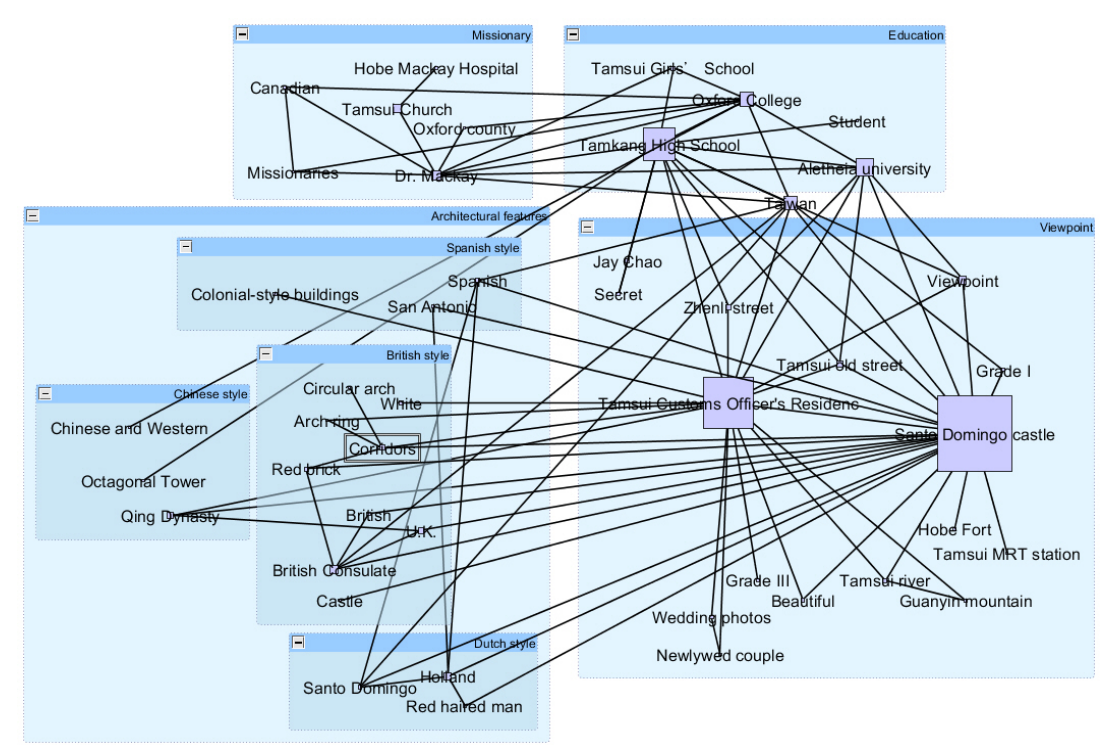

Figure 4. Association analysis of multiple viewpoints.

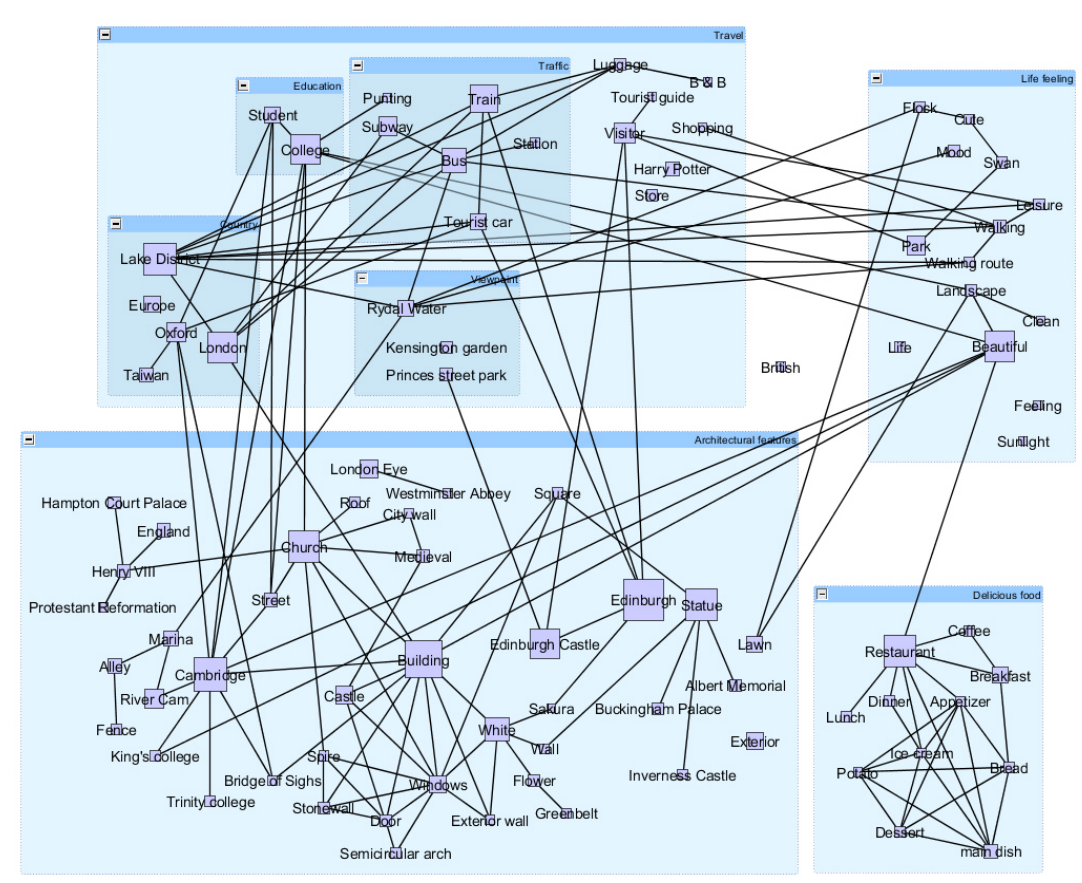

Figure 5. Association analysis of "U.K.”.

From Figure 5, comparing the words of the authors can find out that the characteristics of British building in U.K. are very similar with Tamsui. And the low frequency words in foods are main dish, ice cream, potato et al., and in leisure time are garden, walking, flock, swan, park et al., there are used to describe the fascinated life in the British manor. Therefore, the researchers can conclude that Taiwanese is not only interesting in beauty of architectures, but also staring to interest in enjoying leisure time by British lifestyle to richen the travel.

1) Combination: Link innovative ideas to extract uses of these services from the lead users

The authors compare Figure 4 with Figure 5, and results are presented on Table 1. From Table 1, the words of British building and history in Tamsui and U.K. are very similar. However, these results present that travelers try to enjoy the British lifestyle in British manor. Therefore, these new behaviors are discovered, and there will be the innovation for Tamsui traveling business. 
Table 1. Compare the traveling between Tamsui and U.K.

\begin{tabular}{|c|c|c|}
\hline & Tamsui & United Kingdom (U.K.) \\
\hline Scenic spots & $\begin{array}{l}\text { Fort Santo Domingo, Oxford College, Tamkang High School, } \\
\text { Tamsui Customs Officer’s Residenc, Tamsui Girls' School }\end{array}$ & London, Edinburgh, Cambridge \\
\hline Architectural features & $\begin{array}{c}\text { Castle, Semicircular Arch, White, Corridors, Red Brick, } \\
\text { Octagonal Tower et al. }\end{array}$ & $\begin{array}{l}\text { Castle, Semicircular Arch, White, Corridors, } \\
\text { Greenbelt, Spire, Medieval, Statue, Stonewall et al }\end{array}$ \\
\hline History & $\begin{array}{l}\text { Colonial History (Holland, Span, U.K.), Dr. Mackay } \\
\text { (Christianity and Education) }\end{array}$ & Henry VIII \\
\hline Lifestyle & Roam among the Tribes (Garden, Walking) & Leisure (Garden, Walking, Sheep, Swan, Park et al.) \\
\hline Foods & Null & Main Dish, Ice Cream, Potato et al. \\
\hline
\end{tabular}

Roam among European colonial tribe and remembering Dr. Mackay is the traditional Tamsui travel. In present paper, we fuse Taiwan local information with England's information to generate the Taiwan with England traveling or consuming style for Taiwanese. The new story includes that implement the complementary words, i.e. main dish, ice cream, French fries. It means that the travelers are not only can enjoy British sightseeing, but also can enjoy the British lifestyle in British manor, and there will be the innovation for Tamsui traveling business. And then, authors created an advertising scenario, as following article:

You walk along Fort San Domingo, the red-brick building with its historical significance featuring various colonial stories, and get into the Oxford College located at Aletheia University to experience an integration of Eastern and Western culture and to really understand the spiritual teachings of Reverend Mackay. You then follow Zhenli Street through various old trees to the Little White House. You will see couples of lovers are recording down their romantic stories through video cameras. You feel tired of walking yet? Go to the Missionary House (Mackay' old residence) and enjoy the European-style gardens, bungalows, British-style dishes (fish \& chips, three-layer cakes, British-style tea, and a cup of hot Latte). It is your spiritual home and a place you can really feel relaxed.

Present paper wanted to discuss from three directions, traveling value, traveling experience and traveling intention, to understand the advertising scenario discovered by our model, it will be influence consumers to accept a new traveling plan, as shown on Table 3 . Then, authors used purposive sampling and a traveling questionnaire to collect the data from Tamsui MRT station and the Internet, from 2013/3/23-2013/4/4. Total 89 questionnaires, were collected, after data pre-processing one invalid questionnaire was sift out.

Compare Means One-Sample T-test (see Table 2) is used to examine the sensitivity of traveling value, traveling experience and traveling intention, to understand our model how to influence the travelers. The average value is lower than 3.5, and all attributes are significant, this means that over a half examined travelers are accepting our model suggestions.

After previously analysis, even authors knew that a half of travelers can accept our advertising scenario, we still not knew the influencing power of our model. Then, two steps classification method was used to investigate the number of clusters can be classified. There are two clusters, high score and low score. K-means is used to investigate who belong the high score cluster (55) or low score cluster (33). And there static characteristics were shown in Table 3.

The high score cluster is near 4, but low score cluster is near 3 in attribute of traveling value, as shown on Table 4. The difference of perceiving traveling value between members of high score cluster and low score cluster was the same as the [15]'s experiment: the innovative product could induce the innovators to accept innovative product and to create the innovative usefulness, but imitators always waited for imitating the innovators' consuming behaviors. Moreover, the members of high score cluster arrive $63 \%$ of total travelers, and the experimental result of traveling intention could help authors to find that the travelers in high score cluster, who had higher intention to introduce the innovative traveling scenario for their family or friends than the travelers in low score cluster. Used Rogers' innovation diffusion model to explain these experimental results, the innovation is already cross the chasm to influence the early majority accept innovative product. And this kind experiment is very important for travelers become a lead user. Then, in present paper, the travelers used their traveling experience to evaluate innovative traveling scenario, the travelers in high score cluster they did not so surprise, as a result, "Determinants of User Innovation and Innovation Sharing in a Local Market", think of the innovation 
Table 2. Comparing means one-sample t-test.

\begin{tabular}{ccccc}
\hline Dimension & Mean & & \multicolumn{2}{c}{ Sig. } \\
\cline { 3 - 4 } & & Test value $=3.0$ & Test value $=3.25$ & $0.000^{* * *}$ \\
Traveling Value & 3.593 & $0.000^{* * *}$ & $0.019^{*}$ & 0.157 \\
Traveling Experience & 3.411 & $0.000^{* * *}$ & $0.000^{* * * *}$ \\
Traveling Intention & 3.730 & $0.000^{* * *}$ & $0.000^{* * *}$ \\
\hline
\end{tabular}

${ }_{\mathrm{p}}^{*}<0.05,{ }^{* *} \mathrm{p}<0.01,{ }^{* * *} \mathrm{p}<0.001$.

Table 3. The classification of the high score cluster and low score cluster.

\begin{tabular}{ccc}
\hline & High score cluster & Low score cluster \\
\hline N & 33 & 55 \\
Mean & 3.04 & 3.90 \\
Percentage & $37.5 \%$ & $62.5 \%$ \\
\hline
\end{tabular}

Table 4. Compare the mean of high score cluster with low score cluster.

\begin{tabular}{cccc}
\hline Dimension & & Mean & \\
\cline { 2 - 3 } & High score cluster & Low score cluster \\
\hline Traveling Value & 3.945 & 3.006 & 0.326 \\
Traveling Experience & 3.753 & 2.842 & 3.261 \\
Traveling Intention & 4.011 & 3000 \\
\hline
\end{tabular}

diffusion from the perspective of the early adopters [3].

As previous discussion, the experimental results of present paper evidences that our knowledge spiral model is not only can use text mining to process big textual data and to create an innovative service. In addition, the processes of our model like the behaviors of lead users, the system help authors to look for something interesting information, and then, use their knowledge and skills to create new service for majority, that will be a business chance to win a market. Of course, the experimental results of innovative traveling scenario can catch 63\% travelers to evidence that our model can find out the good business chance to win the market.

\section{Conclusion}

In Web 2.0, however, the consumers can easily share their consuming information on the Internet. Present paper most wants to evidence that how to use big consuming data as lead users work to create an innovative service and let early majority to accept it, finally, which also will be a business chance for wining a market. For this reason, the authors develop an Internet Document based knowledge spiral model under Web 2.0 environment, and then, authors collect and analyze their data for contacting a lot of lead users' idea, and spiral process help them to bridge with other related lead users' idea for combining an innovative service scenario or new knowledge. At last, the case of Tamsui traveling is used to examine our model. After spiral knowledge analysis, authors get British style Tamsui traveling, and examine the traveler to understand their traveling intention. The experimental result pointed over 60\% travelers want to visit the British style Tasmsui, it evidences our model and is very useful for creating innovative service.

\section{References}

[1] Rogers, E.M. (2003) Diffusion of Innovations. Free Press, New York.

[2] Nonaka, I. (1994) A Dynamic Theory of Organizational Knowledge Creation. Organization Science, 5, $14-37$. http://www.jstor.org/stable/2635068?seq=1\#page scan tab contents http://dx.doi.org/10.1287/orsc.5.1.14 
[3] Morrison, P.D., Roberts, J.H. and von Hippel, E. (2000) Determinants of User Innovation and Innovation Sharing in a Local Market. Management Science, 46, 1513-1527.

http://pubsonline.informs.org/doi/abs/10.1287/mnsc.46.12.1513.12076

http://dx.doi.org/10.1287/mnsc.46.12.1513.12076

[4] Etgar, M. (2008) A Descriptive Model of the Consumer Co-Production Process. Journal of the Academy of Marketing Science, 36, 97-108. http://link.springer.com/article/10.1007\%2Fs11747-007-0061-1 http://dx.doi.org/10.1007/s11747-007-0061-1

[5] O’Hern, M.S. and Rindfleisch, A. (2009) Customer Co-Creation: A Typology and Research Agenda. Review of Marketing Research, 6, 84-106. http://dx.doi.org/10.1108/S1548-6435(2009)0000006008 http://www.emeraldinsight.com/doi/pdfplus/10.1108/S1548-6435\%282009\%290000006008

[6] Price, L.L. and Ridgway, N.M. (1982) Use Innovativeness, Vicarious Exploration and Purchase Exploration: Three Facets of Consumer Varied Behavior. AMA Educator's Conference Proceedings, 56-60.

[7] Franke, N., Keinz, P. and Steger, C.J. (2009) Testing the Value of Customization: When Do Customers Really Prefer Products Tailored to Their Preferences? Journal of Marketing, 73, 103-121. http://journals.ama.org/doi/abs/10.1509/jmkg.73.5.103 http://dx.doi.org/10.1509/jmkg.73.5.103

[8] Lin, M.H. and Hong, C.F. (2011) Opportunities for Crossing the Chasm between Early Adopters and the Early Majority through New Uses of Innovative Products. The Review of Socionetwork Strategies, 5, 27-42. http://link.springer.com/article/10.1007\%2Fs12626-011-0019-0 http://dx.doi.org/10.1007/s12626-011-0019-0

[9] Strauss, A.C. and Corbin, J.M. (1998) Basics of Qualitative Research: Techniques and Procedures for Developing Grounded Theory. 2nd Edition, Sage Publications, Inc., London.

[10] Ernst, H., Hoyer, W.D., Krafft, M. and Soll, J.H. (2010) Consumer Idea Generation. Working Paper, WHU, Vallendar.

[11] Hoyer, W.D., Chandy, R., Dorotic, M., Krafft, M. and Singh, S.S. (2010) Consumer Concretion in New Product Development. Journal of Service Research, 13, 283-296. http://jsr.sagepub.com/content/13/3/283.abstract http://dx.doi.org/10.1177/1094670510375604

[12] Hauser, J., Tellis, G.J. and Griffin, A. (2006) Research on Innovation: A Review and Agenda for Marketing Science. Marketing Science, 25, 686-717. http://pubsonline.informs.org/doi/abs/10.1287/mksc.1050.0144?journalCode=mksc http://dx.doi.org/10.1287/mksc.1050.0144

[13] Muniz, A.M. and O’Guinn, T. (2001) Brand Community. Journal of Consumer Research, 27, 412-432. http://www.jstor.org/stable/10.1086/319618 http://dx.doi.org/10.1086/319618

[14] O’Reilly, T. (2007) What Is Web 2.0: Design Patterns and Business Models for the Next Generation of Software. Communications \& Strategies, 65, 17-37. http://papers.ssrn.com/sol3/papers.cfm?abstract id=1008839

[15] Bass, F.M. (1969) A New Product Growth for Model Consumer Durables. Management Science, 15, 215-227. http://pubsonline.informs.org/doi/abs/10.1287/mnsc.15.5.215 http://dx.doi.org/10.1287/mnsc.15.5.215 